\title{
CONCEITOS DE IDENTIDADE SURDA NO DISCURSO MIDIÁTICO SOBRE A INCLUSÃO EDUCATIVA NA ALEMANHA
}

\section{CONCEPTS OF DEAF IDENTITY IN MEDIA DISCOURSE ON INCLUSIVE EDUCATION IN GERMANY}

\section{Romana Castro Zambrano* Cleide Emília Faye Pedrosa**}

\section{RESUMO}

O artigo propõe uma análise da conceitualização da identidade coletiva de surdos no discurso midiático sobre a educação inclusiva entre 2011 e 2015 na Alemanha. Na história da educação alemã, a identidade linguística dos surdos tem sido preponderantemente ignorada. Os surdos, socialmente definidos como pessoas com deficiência, foram ensinados geralmente em escolas especiais. A Alemanha se comprometeu a mudar essa situação com a ratificação da Convenção sobre os Direitos das Pessoas com Deficiência das Nações Unidas em 2008. Em nossa pesquisa, baseamo-nos teoricamente na Análise Crítica do Discurso (ACD), presumindo uma relação dialética entre o discurso e a sociedade (FAIRCLOUGH, WODAK, 1997), na qual a cognição social serve de interface (VAN DIJK, 1997, 2002, 2003). Partindo do pressuposto de que, no debate midiático sobre a inclusão, as identidades das pessoas envolvidas se representam de uma maneira estereotipada, orientamo-nos metodologicamente pela ideia dos Modelos Cognitivos Idealizados (MCI) (LAKOFF, 1987), considerando seu caráter sociocognitivo. Os resultados da análise mostram um mosaico de diferentes conceitualizações da identidade surda, predominantemente sob uma perspectiva alheia.

Palavras-chave: análise crítica do discurso; identidade surda; educação inclusiva.

\section{ABSTRACT}

The paper proposes an analysis of the conceptualization of deaf collective identity in the media discourse about inclusive education between 2011 and 2015 in Germany. In the history of German education, the linguistic identity of the deaf has been mainly ignored. The deaf, socially defined as people with disabilities, were generally taught in special schools. By the ratification of the Convention on the Rights of Persons with Disabilities of the United Nations in 2008, Germany has undertaken to change this situation. Theoretically, our research is guided by Critical Discourse Analysis (CDA), assuming a dialectical relationship between discourse and society (FAIRCLOUGH, WODAK, 1997), in which social cognition serves as an interface (VAN DIJK, 1997, 2002, 2003). Methodologically, we base our study on a socio-cognitive idea of Idealized Cognitive Models (ICM) (LAKOFF, 1987),

\footnotetext{
* Universidade Federal de Sergipe, Aracajú (SE), Brasil. r.castro@gmx.net

** Universidade Federal de Sergipe, Aracajú (SE), Brasil. cleidefayepedrosa@oi.com.br
} 
presupposing that the identities of the people involved in the media debate about inclusion are represented in a stereotypical way. The results of the analysis show a mosaic of different conceptualizations of deaf identity, predominantly from the perspective of others.

Keywords: critical discourse analysis; deaf identity; inclusive education.

\section{INTRODUÇÃO}

A educação inclusiva pode ser entendida como uma medida para garantir uma educação de qualidade para todos, mas também como uma maneira de se acostumar, desde criança, a uma sociedade heterogênea, em que a diversidade é algo habitual.

Enquanto em muitos países a Declaração de Salamanca de 1994 causou uma reestruturação do sistema educativo a favor da inclusão, na Alemanha, o conceito da educação inclusiva só foi adotado em 2008, quando o país ratificou a Convenção sobre os Direitos das Pessoas com Deficiência das Nações Unidas (SCHUMANN, 2014). Com a ratificação, houve o início de um debate midiático sobre a educação inclusiva que continua até a atualidade. Nesse discurso midiático, encontram-se argumentações pró e contra a educação inclusiva, muitas vezes relacionadas com certa representação social das pessoas com deficiência. Presumimos, portanto, que o debate midiático constrói uma imagem desses grupos sociais que influi também na sua identidade coletiva.

No estudo aqui relatado, propomos uma análise dessas representações e seus possíveis efeitos para a constituição identitária, focalizando os surdos. A pesquisa orienta-se teoricamente pela Análise Crítica do Discurso (ACD) (FAIRCLOUGH, WODAK, 1997; VAN DIJK, 1997, 2002, 2003), compreendendo-a como um programa emancipatório para analisar relações de poder no discurso e dar "voz" aos excluídos. No cômputo geral, na Alemanha, os surdos são socialmente definidos como pessoas com deficiência. Essa definição contradiz a autopercepção de grande parte dos surdos alemães, posto que muitos se percebem como parte da comunidade surda, de uma minoria linguística ou de uma subcultura ${ }^{1}$, enquanto poucos se veem como deficientes (SCHULTEIS, 2006). A Convenção exige explicitamente uma promoção da identidade linguística surda no contexto da inclusão educativa. Portanto, considera-se também se e como esses aspectos são tratados no discurso midiático.

\footnotetext{
1 Para Schulteis (2006), o termo subcultura não apresenta uma conotação negativa. Segundo a autora, subculturas são grupos minoritários que compartilham certos valores e uma identidade coletiva.
} 


\title{
1. A CONSTRUÇÃO DISCURSIVA DE IDENTIDADES
}

"Não é difícil concordar com o fato de que, do ponto de vista sociológico, toda e qualquer identidade é construída", constata Castells (1999, p. 23). Considerando os estudos do Interacionismo Simbólico (GOFFMAN, 1959; MEAD, 1934), podemos afirmar que a linguagem em uso desempenha um papel crucial nos processos construtivos da identidade individual. Mas qual inter-relação podemos observar entre o discurso e as identidades coletivas?

Com base na Análise Crítica do Discurso (ACD) ${ }^{2}$, entendemos aqui sob o termo discurso uma prática social que inclui tanto o uso da linguagem escrita, oral ou gestual, como qualquer outra forma de comunicação.

\begin{abstract}
Descrever o discurso como prática social implica uma relação dialética [...]. Uma relação dialética é uma relação de duas direções: o evento discursivo é moldado pela situação, por instituições e estruturas sociais, mas também as molda. Dito de outra maneira, o discurso é socialmente constitutivo, bem como socialmente moldado: ele constitui situações, objetos de conhecimento e as identidades sociais de pessoas e grupos de pessoas como também as relações entre elas e eles. (FAIRCLOUGH, WODAK, 1997, p. 258, grifo dos autores, tradução nossa) $)^{3}$
\end{abstract}

Considerando essa relação dialética, propomos, em consonância com van Dijk $(1997,2002,2003)$, que a influência da sociedade sobre o discurso, e viceversa, explica-se pela interface da cognição social. Segundo o autor, a cognição social pode ser entendida como um sistema mental que se forma no contexto social e, portanto, é compartilhada pelos membros de certas comunidades e grupos. O sistema mental divide-se em vários subsistemas, como atitudes, ideologias, normas e valores. Um dos subsistemas, o saber, ocupa uma posição especial, pois se caracteriza por ser considerado a verdade e, em consequência, constitui a realidade de certas comunidades discursivas.

Tomando em conta essas bases teóricas, percebemos que a construção discursiva de saberes pode se entender como uma forma de estabelecer certa visão

2 Embora as diversas abordagens da Análise Crítica do Discurso (ACD) tenham certos aspectos em comum (WODAK; MEYER, 2009b), podem-se constatar diferenças teóricas e metódicas (WODAK ; MEYER, 2009a). Sem dúvida, pode-se afirmar que os representantes mais influentes da ACD na Europa e na América Latina são Norman Fairclough (1992, 1995, 2003), Teun A. van Dijk (1997, 2002, 2003) e Ruth Wodak (1996, 2009).

3 Texto original em inglês: "Describing discourse as social practice implies a dialectical relationship [...]. A dialectical relationship is a two-way relationship: the discursive event is shaped by situation, institutions and social structures, but it also shapes them. To put the same point in a different way, discourse is socially constitutive as well as socially shaped: it constitutes situations, objects of knowledge, and the social identities of and relationships between people and groups of people." 
acerca do mundo em desfavor de outra. Isto posto, sublinha-se que o discurso sempre está vinculado com relações de poder. Porém, deve-se compreender a imposição de um discurso e, com isso, a produção de saberes, como um processo de negociação entre os membros de uma comunidade discursiva (SPITZMÜLLER; WARNKE, 2011).

Voltando à definição de Fairclough e Wodak (1997) dada acima, nota-se que os autores destacam que o discurso molda identidades sociais. Neste contexto, cabe frisar que o termo identidade social é utilizado para conceitos diferentes: ou entendese como parte da identidade individual relacionada com a pertença a certo grupo ou se refere à identidade desse grupo mesmo ou abarca os dois conceitos mencionados sem diferenciar entre os níveis individual e coletivo (KLANDERMANS, 2002; SMITH, 2008).

Em conformidade com Tajfel (1981), entendemos aqui a identidade social como um conceito desenvolvido pelo indivíduo por identificar-se com um determinado grupo. Ao contrário, denomina-se identidade coletiva a identidade de um grupo de.

\begin{abstract}
Sob uma identidade coletiva ou identidade do nós entendemos a imagem que um grupo cria de si, e com que seus membros se identificam. Identidade coletiva é uma questão de identificação por parte dos indivíduos envolvidos. Essa identidade não existe "em si", mas apenas na medida em que certos indivíduos professam a identificação com ela. Ela é tão forte ou tão fraca, quanto ela está viva na consciência dos membros do grupo e consegue motivar seu pensamento e seu agir. (ASSMANN, 2000, p. 132, grifo do autor, tradução nossa) ${ }^{4}$
\end{abstract}

A identidade social está, portanto, vinculada à identidade coletiva no sentido de que ela se constitui pela identificação com essa identidade coletiva. Com isso, o indivíduo assume as características do grupo para si.

De acordo com Assmann (2000), a identidade coletiva encontra-se fortemente associada a aspectos como conhecimento, consciência e reflexão guardados na memória coletiva. ${ }^{5}$ Assim, podemos constatar que o conceito está inter-relacionado com a cognição social e, destarte, também com o discurso.

4 Texto original em alemão: "Unter einer kollektiven oder Wir-Identität verstehen wir das Bild, das eine Gruppe von sich aufbaut, und mit dem sich deren Mitglieder identifizieren. Kollektive Identität ist eine Frage der Identifikation seitens der beteiligten Individuen. Es gibt sie nicht 'an sich', sondern immer nur in dem Maße, wie sich bestimmte Individuen zu ihr bekennen. Sie ist so stark oder so schwach, wie sie im Bewußtsein der Gruppenmitglieder lebendig ist und deren Denken und Handeln zu motivieren vermag."

5 Jan $(1988,2000)$ e Aleida Assmann (1988) definem o conceito da memória coletiva como saberes coletivos compartilhados pelos membros de um grupo determinado. Eles baseiam seu conceito na teoria de Halbwachs $(1966,1985)$. 
Embora Assmann (2000) destaque que a identidade coletiva se constrói pela autoimagem de uma comunidade, deve-se considerar que tanto as identidades individuais (GOFFMAN, 1959) como as identidades coletivas (GIESEN, 1999) se constituem por uma combinação de autopercepção e de percepção alheia. Hall (1996) problematiza a influência do discurso dominante sobre a constituição de indivíduos e grupos, afirmando que não se tratava somente de categorizar pessoas e grupos como o outro, mas também de impor esses conhecimentos ao outro. Convém lembrar que essa problemática também se aplica ao discurso sobre surdos.

\section{IDENTIDADES COLETIVAS E ESTEREÓTIPOS NO CONTEXTO DA EDUCAÇÃO INCLUSIVA}

A educação inclusiva pode ser entendida como uma medida para estabelecer a igualdade de oportunidades tanto no quadro educacional como na vida pósescolar, garantindo a mesma qualidade de ensino para todos (WERNING, 2014).

Além disso, a educação inclusiva faz parte da inclusão geral que, compreendida como um conceito ético-filosófico, defende a ideia de aceitar a singularidade de cada pessoa dentro de uma sociedade heterogênea (KRÖG, 2005). Consequentemente, podemos constatar que converter uma sociedade em uma sociedade inclusiva também significa uma redefinição de sua identidade coletiva. Esta deve abarcar todos os seus membros e se distanciar de uma identidade coletiva baseada na maioria, classificando-a esta como normal. Segundo Mantoan (2004), os sistemas escolares segregativos ou excludentes justificam-se por meio dessas identidades normalizadas. Conforme a autora, os processos de normalização geram um padrão de uma identidade normal baseada em características positivas e arbitrariamente selecionadas que servem para consolidar hierarquias entre seres humanos.

Tendo em vista os estudos de Tajfel (1981), observa-se que essa construção identitária de grupos está relacionada com a categorização humana, que se realiza principalmente de uma forma simplificada e estereotipada.

Em conformidade com Bourhis e Maass (2005), entendemos aqui sobre o termo estereótipo as crenças compartilhadas pelos membros de certo grupo sobre as características do próprio ou de outros grupos. Para os autores, os estereótipos resultam de processos de categorização e permitem organizar as informações complexas sobre o mundo em esquemas e unidades mais inteligíveis. Desse modo, também se categorizam pessoas quanto a sua nacionalidade, seu gênero, sua orientação sexual etc. Notamos que existe também a categorização de pessoas com 
e sem deficiência ${ }^{6}$, as últimas classificadas como normais. Estereótipos podem ser tanto positivos como negativos e se convertem em disfuncionais e problemáticos quando são projetados de maneira indiferenciada a todo membro de certo grupo sem levar em conta suas diferenças individuais (BOURHIS, MAASS, 2005). Termos ligados ao estereótipo são preconceito e discriminação. Enquanto o primeiro termo se refere a um conceito afetivo e emocional, muitas vezes negativo, a discriminação entende-se como uma espécie de comportamento em concordância com os estereótipos e preconceitos (BOURHIS, MAASS, 2005).

Visto que essa perspectiva aborda, sobretudo, o aspecto cognitivo, destacamos, portanto, que os estereótipos são também uma questão social e discursiva. Nem estereótipos, nem preconceitos formam-se individualmente, mas se adquirem no processo de socialização e se (re)produzem e modificam discursivamente (VAN DIJK, 1984).

$\mathrm{Na}$ vida escolar, os estereótipos e preconceitos podem levar a consequências graves para os alunos afetados, visto que se nota uma correlação entre estereótipos e a avaliação negativa de alunos (PANESAR, 2015). Por um lado, essa correlação explicase pela teoria da profecia autorrealizada, que afirma que uma falsa definição inicial provoca um comportamento correspondente a esta e, em consequência, a definição falsa se converte em uma definição verdadeira (MERTON, 1948). Em decorrência disso, a partir dos anos 60 do século passado, realizaram-se experiências no contexto escolar, que sustentavam a ideia de que professores transmitem inconscientemente suas expectativas aos alunos. Quando as expectativas são positivas levam a um melhor desempenho dos alunos, chamado de Efeito Pigmaleão (ROSENTHAL; JACOBSON, 1968), enquanto o Efeito Golem descreve as expectativas negativas e seus efeitos correspondentes (BABAD; INBAR; ROSENTHAL, 1982).

Outra explicação para a correlação entre a pertença a certo grupo social e o fracasso escolar é dada pela teoria da ameaça dos estereótipos. Segundo essa teoria, a identificação com um grupo estereotipado de modo negativo influencia o desempenho dos alunos (STEELE, 1997; STEELE; ARONSON, 1995). A teoria interpreta esse fenômeno, explicando que há certa ansiedade das pessoas em confirmarem os estereótipos negativos. Essa ansiedade, por sua vez, causa uma diminuição do desempenho.

\footnotetext{
6 Em concordância com a nomenclatura oficial da legislação brasileira (vide, por exemplo, BRASIL, 2014), neste artigo, utilizamos os termos alunos/pessoas com deficiência. Porém, convém lembrar que - em consideração de surdos que rejeitam definir-se como deficientes - essa terminologia pode ser problemática (SCHULTEIS, 2006). Além disso, destaca-se que, no discurso alemão, encontramse também as expressões alunos/pessoas com necessidades educacionais especiais. Somente com referência a tais exemplos, será usada essa terminologia.
} 
Relacionando essas reflexões teóricas com o fato de que escolas de apoio fundamentam-se no estereótipo social de que seus alunos - independentemente da natureza de sua deficiência - não têm a capacidade de concluir uma escola regular, pode-se deduzir que o projeto de inclusão escolar pode fracassar devido à persistência desse estereótipo.

\section{ANALISANDO IDENTIDADES E ESTEREÓTIPOS NO QUADRO DA ACD}

Nos últimos anos, desenvolveram-se várias abordagens da ACD integrando novos métodos linguísticos (REISIGL; ZIEM, 2014; WODAK; MEYER, 2015). Entre outras, existe uma tendência notável à Linguística Cognitiva (LC) (AUTOR, 2015; CHARTERIS-BLACK，2004; HART，2010，2014; KOLLER，2005; O'HALLORAN, 2003), aplicando, por exemplo, a teoria do frame (FILLMORE, 1982), dos espaços mentais (FAUCONNIER, 1994), da integração conceitual (FAUCONNIER; TURNER, 2002) ou das metáforas conceituais (LAKOFF; JOHNSON, 1980).

Posto que definimos a identidade coletiva como um construto discursivo baseado em conhecimentos e saberes, percebemos que a LC destina-se, entre outras, à questão da cognição social (CASTRO ZAMBRANO, 2015). No contexto da pesquisa aqui focalizada, consideramos importantes tanto a categorização como as características atribuídas a essas categorias. Partimos, portanto, da teoria dos Modelos Cognitivos Idealizados (MCI) introduzida por Lakoff (1987).

MCI são modelos para explicar como se estruturam saberes e conhecimentos. Segundo Lakoff (1987), essa estruturação realiza-se de uma maneira prototípica. Pode-se classificar diferentes efeitos prototípicos, por exemplo, o efeito prototípico simples, que resulta de uma simplificação da definição de uma categoria. Um exemplo dado por Lakoff (1987) é a categoria bachelor em inglês, o qual está definido como "um homem não casado". A simplificação consiste em ignorar que existem pessoas que se encaixam nessa definição, mas sem corresponder ao que se entende como bachelor, por exemplo, padres católicos. Outro efeito prototípico refere-se a conceitos que se baseiam em modelos complexos (cluster models) como, por exemplo, mãe, definida, conforme Lakoff, por diferentes modelos. Além da definição básica correspondente ao modelo de nascimento (pessoa que dá a luz), existem outros modelos, tais como: modelo genético, modelo de criação, modelo matrimonial ou modelo genealógico. O importante desses modelos complexos é que o conjunto deles representa o caso típico de uma mãe, embora uma pessoa não precise se 
encaixar em todos esses modelos individuais para ser uma mãe. Partindo do modelo central de mãe, podem-se desenvolver, socialmente influenciadas, subcategorias, chamadas de categorias radiais, como, por exemplo, a madrasta ou a mãe adotiva. Dessas categorias sociais nascem, por sua vez, novos efeitos prototípicos.

Conforme Lakoff (1987), existem, além disso, efeitos prototípicos que surgem de relações metonímicas. Um desse é o estereótipo social em que uma subcategoria se reconhece socialmente como representante para uma categoria inteira. Ainda no caso da mãe, o autor propõe o estereótipo de dona de casa. Então, de acordo com o autor, existe certa expectativa social de que a mãe seja dona de casa, enquanto a mãe que não é dona de casa nos parece mais excepcional. Também pode-se identificar efeitos prototípicos baseados no melhor exemplo. Nesse caso, considera-se uma subcategoria mais representante do que outra, por exemplo: um pombo é um pássaro típico; um pinguim, não. Um caso diferente é o caso ideal que não precisa ser típico nem estereotípico, como, por exemplo, o marido socialmente percebido como marido ideal: é atraente, carinhoso, um bom pai, tem sucesso no trabalho, ajuda em casa etc. O efeito prototípico padrão (paragon) refere-se a um caso singular que representa de maneira ótima o caso ideal, por exemplo, Elvis Presley como o rei do rock ' $n$ ' roll. Um exemplo saliente, ao contrário, é quando se generaliza a partir de um caso conhecido a uma categoria, por exemplo, de um amigo vegetariano a todos os vegetarianos. A lista de efeitos prototípicos de Lakoff não é definitiva, trata-se somente de alguns exemplos identificados. Portanto, podem-se encontrar no discurso outros efeitos adicionais.

Comparando-se os fenômenos descritos por Lakoff (1987) com a definição de estereótipo de Bourhis e Maass (2005) proposta anteriormente, nos damos conta de que a maioria dos efeitos prototípicos encaixa-se nesse conceito. Enquanto Lakoff limita o conceito de estereótipos sociais a casos especiais, Bourhis e Maass (2005) remetem o conceito a crenças simplificadas sobre um grupo em geral. Essa circunstância pode se relacionar com a observação de Geeraerts (2006) de que as noções de protótipo e estereótipo, às vezes, descrevem o mesmo fenômeno. ${ }^{7}$

Visto que Lakoff, sobretudo em obras posteriores (LAKOFF; JOHNSON, 1999), explica fenômenos cognitivos com experiências corporais e físicas, destacamos aqui o caráter sociocognitivo de MCI (KRISTIANSEN, 2008). Outrossim, ressaltamos que os MCI manifestam-se discursivamente. Levando isso em conta, na pesquisa aqui relatada, analisamos a construção da identidade surda

7 Consideramos que a ideia principal dos $\mathrm{MCI}$, aplicada aqui, explica efeitos prototípicos e representa uma ferramenta apropriada para analisar categorias sociais no discurso. Contudo, assumimos que a teoria, quanto a alguns detalhes, é inconsistente (ZIEM, 2008). 
a partir da ideia de categorizações formulada na teoria dos $\mathrm{MCI}$, com enfoque em seus efeitos sobre a constituição identitária no discurso midiático alemão no contexto da educação inclusiva.

Para obter uma visão geral, o nosso corpus se constitui a partir de matérias de jornais de importância nacional nas suas versões on-line, e representam diferentes orientações políticas, que vão desde a direita populista, passando pela orientação intelectual conservadora e neoliberal até a intelectual de esquerda: BILD, DIE ZEIT, Frankfurter Allgemeine Zeitung (F.A.Z.) e Süddeutsche Zeitung (SZ). Consideram-se artigos publicados de 2011 até 2015, posto que em 2011 foi apresentada uma nova diretiva sobre o ensino de alunos com deficiência. Para situar os resultados da análise no contexto histórico-social, introduzimos, em continuação, a história da educação para surdos e a educação inclusiva na Alemanha.

\section{A EDUCAÇÃO PARA SURDOS E A EDUCAÇÃO INCLUSIVA NA ALEMANHA}

A educação estruturada de surdos teve início em 1778 com a fundação de um instituto público para surdos em Leipzig. Visto que o diretor Samuel Heinicke era um defensor do método oral, o objetivo principal do ensino era que os surdos aprendessem a língua alemã, enquanto a língua de sinais se usava somente quando fosse inevitável (LÖWE, 1983; VOGEL, 1999). Porém, o método oral foi questionado por alguns professores que optavam pelo uso da língua de sinais ou por uma combinação dessa com a língua alemã. Essa discórdia levou a uma disputa pública entre os professores sobre o melhor método (VOGEL, 1999). No congresso de Milão, o Segundo Congresso Internacional de Educadores de Surdos em 1880, decidiu-se que a língua de sinais deveria ser excluída do ensino a favor de um ensino da língua oral. Essa filosofia do ensino permaneceu como princípio dominante no século XX, apoiada pelas inovações da tecnologia auditiva (GÜNTHER, 2007). A partir de 1975, verifica-se uma tendência a favor do uso de sinais, fundamentada nas pesquisas linguísticas sobre a língua de sinais (WISOTZKI, 2008). Não obstante, isso não significava que seria adotada a língua de sinais em todas as escolas para surdos a partir dessa data. Em 1982, exigia-se oficialmente o bimodalismo, o uso da língua oral acompanhada por sinais, e só em 1993 se iniciou um projeto-piloto bilíngue em uma escola em Hamburgo (GÜNTHER, 2007). Exceto algumas tentativas de integração, no decurso da história da educação para surdos, o ensino realizava-se geralmente em escolas e institutos especiais (LÖWE, 1983). 
Em 2002, a Alemanha reconheceu a língua de sinais alemã (Deutsche Gebärdensprache, DGS) como uma língua distinta (BGG, 2002, \$6, 1), e com a ratificação da Convenção sobre os Direitos das Pessoas com Deficiência das Nações Unidas em 2008, a Alemanha assegurou um "sistema educacional inclusivo em todos os níveis" (ONU, 2012, artigo 24, 1). Os surdos recebem um status especial pela Convenção, posto que os Estados Partes comprometem-se à "facilitação do aprendizado da língua de sinais e promoção da identidade linguística da comunidade surda" (ONU, 2012, artigo 24, 3b), e garantem

que a educação de pessoas, em particular crianças cegas, surdocegas e surdas, seja ministrada nas línguas e nos modos e meios de comunicação mais adequados ao indivíduo e em ambientes que favoreçam ao máximo seu desenvolvimento acadêmico e social. (ONU, 2012, artigo 24, 3b)

Entretanto, para realizar as exigências da Convenção é preciso superar vários obstáculos, entre eles a segregação presente no sistema de educação na Alemanha. Além das escolas de apoio (escolas especiais) com diferentes focos, existem três tipos de escolas diferentes a partir da secundária (Gymnasium, Realschule, Hauptscbule). A qualidade e o enfoque do ensino variam bastante, como demonstra, por exemplo, o fato de que só a conclusão do Gymnasium habilita diretamente para o estudo universitário, enquanto a Hauptschule, que representa o ensino mais básico dos três, qualifica para a formação em escolas profissionalizantes (VIOTTI, 2014) ${ }^{8} \mathrm{O}$ sistema defende o princípio de que se obtêm os melhores resultados educacionais em grupos homogêneos, o qual está diametralmente oposto à ideia do ensino inclusivo.

Outra dificuldade reside na realização uniforme da Convenção em nível nacional, posto que "as responsabilidades legislativa e administrativa sobre educação cabem aos Lander (Estados)" (CAPDEVILLE, 1994, p. 42, grifo do autor). Devido a isso, a interpretação da Convenção e a realização da educação inclusiva variam de um estado federado para o outro (MISSLING; ÜCKERT, 2014).

\section{A IDENTIDADE SURDA NO DISCURSO MIDIÁTICO SOBRE A INCLUSÃO: RE- SULTADOS DA ANÁLISE}

No discurso midiático alemão, com base no corpus coletado, encontram-se diferentes conceitualizações da identidade surda. Por essa razão, as análises e seus resultados serão organizados em subdivisões temáticas.

8 Trata-se de uma descrição simplificada do sistema escolar na Alemanha. Para uma explicação detalhada recomenda-se Viotti (2014). Nota-se também que o sistema está mudando, entre outros motivos, devido à inclusão. 


\title{
5.1. Os surdos como caso especial
}

Nos primeiros fragmentos apresentados, os surdos são tratados como um grupo especial entre as crianças com deficiência. O recorte seguinte discorre sobre o progresso da implementação da Convenção das Nações Unidas nas leis estaduais.

Portanto, em 2017, deve haver apenas três escolas de apoio na cidade de Bremen: aquelas para crianças com deficiências múltiplas e graves, bem como deficientes visuais e auditivos que trabalham principalmente com o Braille ou com a língua de sinais. (BELZ, 2012, tradução nossa $)^{9}$

Um dos primeiros estados federados (Bundesländer) que começou a realizar a inclusão educativa foi Bremen, porém, suas leis não planejaram a inclusão de três subcategorias de pessoas com deficiência, entre elas os surdos que fazem parte do grupo dos deficientes auditivos. O motivo dessa separação explica-se, no fragmento, pelo uso da língua de sinais no ensino. Isto posto, pode-se constatar - indiretamente - o reconhecimento dos surdos como um grupo caracterizado por uma particularidade linguística. No próximo trecho, também se observa uma diferenciação das pessoas com deficiência, dessa vez sem basear-se em leis.

\begin{abstract}
Os surdos são excluídos da comunicação oral sem intérpretes de língua de sinais ou auxiliares técnicos. Para as pessoas com deficiência mental, muitas vezes regras rígidas e prazos significam uma barreira. Por isso, quando se trata de inclusão, não se trata somente de rampas de acesso para cadeirantes. A inclusão também não significa simplesmente colocar crianças com deficiência de volta às classes normais. A mera presença de uma criança com deficiência em uma classe regular não causa efeitos positivos; muitas vezes causa até o oposto do que se esperava. Se não houver mais do que uma integração espacial e se não tiver um apoio específico - então, essa integração é uma apresentação em branco, cujos resultados são desmotivação e resignação. (PRANTL, 2014, tradução nossa) ${ }^{10}$
\end{abstract}

O autor do artigo critica a má interpretação do conceito de inclusão, alertando para seu fracasso, caso não se diferencie as múltiplas particularidades

9 Texto original em alemão: "Bis 2017 soll es deshalb in der Stadt Bremen nur noch drei Förderschulen geben: Jene für schwerst mehrfach behinderte Kinder sowie für Seh- und Hörbehinderte, die vor allem mit Brailleschrift oder Gebärdensprache arbeiten."

10 Texto original em alemão: "Gehörlose Menschen sind ohne Gebärdensprachendolmetscher oder technische Hilfsmittel von lautsprachlicher Kommunikation ausgeschlossen. Für Menschen mit psychischen Beeinträchtigungen stellen oft schon starre Regelungen und Fristen eine Barriere dar. Wenn es um Inklusion geht, geht es also nicht einfach nur um Auffahrtsrampen für Rollstuhlfahrer. Inklusion heißt auch nicht einfach, dass man Kinder mit Behinderung wieder in normale Schulklassen steckt. Die bloße Anwesenheit eines Kindes mit Behinderung in einer Regelklasse bewirkt nicht viel; oft bewirkt sie sogar das Gegenteil von dem, was man sich erhofft. Wenn nicht mehr passiert als räumliche Eingliederung, wenn es dann keine gezielte Förderung gibt - dann ist solche Integration leere Präsentation, die Demotivation und Resignation zur Folge hat." 
das pessoas com deficiência. Com isso, conceitualiza diferentes grupos de pessoas com deficiência, entre eles, os surdos. Contrariamente ao artigo anterior, não se menciona o uso da língua de sinais na aula. Aqui essa língua é considerada mais como um meio para possibilitar a comunicação entre o professor e o aluno, mediada por um intérprete. A circunstância de que a identidade linguística dos surdos é em grande parte ignorada é também atestada pela menção aos auxiliares técnicos que, nesse artigo, parecem ter o mesmo valor que a mediação do ensino através de um intérprete. Uma atitude parecida encontra-se no trecho seguinte.

\begin{abstract}
Alunos com deficiência têm o direito à inclusão e este também é o objetivo, enfatiza Josef Kraus, presidente da Associação Alemã de Professores, mas, ao mesmo tempo, ele exige mais diferenciação. "Há formas de deficiências, onde a inclusão não é necessariamente a melhor forma." Segundo Kraus, podem-se encontrar as soluções estruturais ou técnicas para deficiências físicas ou deficiências sensoriais [...]. (EBITSCH, 2012b, tradução nossa) ${ }^{11}$
\end{abstract}

Afirmando que a inclusão não é adequada para crianças com qualquer tipo de deficiência, o presidente da Associação Alemã de Professores define os surdos, aqui incluídos no grupo das pessoas com deficiências sensoriais, como deficientes incluíveis. Essa inclusão, de acordo com as palavras do presidente, poder-se-ia realizar através de "soluções estruturais ou técnicas". Em vista de que o presidente da Associação não especificar essas soluções, pode-se deduzir que se refere, por exemplo, à tecnologia auditiva. Posto que a língua de sinais não recebeu nenhuma menção, pode-se concluir que a identidade linguística dos surdos foi completamente desconsiderada nesse artigo. Por outro lado, nota-se que os surdos são categorizados como alunos com deficiência, mas essa categoria apresenta-se de um modo diferenciado, contradizendo o estereótipo de que todos os alunos com deficiência não conseguem estudar em escolas regulares. No próximo artigo, um jornal dá "voz" a uma pessoa surda em uma entrevista. Convém informar que a entrevistada surda é membro ativo do Partido Pirata, partido político alemão.

Julia Probst: Eu respondi no show "log in" a perguntas sobre o Partido Pirata. [...] Na manhã seguinte, li no Twitter que a minha voz não tinha soado bem. Alguns usuários escreveram que eu deveria ter utilizado apenas a língua de sinais.

ZEIT ONLINE: Que tipo de usuários eram essas pessoas?

Probst: Muitos eram surdos também. Eles disseram que quando eu falo sobre a inclusão, eu deveria fazê-lo por meio da língua de sinais. Outros usuários não deficientes escreveram que a

11 Texto original em alemão: "Behinderte Schüler hätten ein Recht auf Inklusion und dies sei auch das Ziel, betont Josef Kraus, Präsident des Deutschen Lehrerverbands, fordert aber zugleich aber eine stärkere Differenzierung. 'Es gibt Formen von Beeinträchtigungen, wo Inklusion nicht unbedingt der optimale Weg ist.' Bei körperlichen Behinderungen oder Sinnesschädigungen könne man etwa bauliche oder technische Lösungen finden [...]." 
voz é a ferramenta mais importante de um político. Mas a língua de sinais não é a minha língua materna. E eu quero falar!

ZEIT ONLINE: Essa crítica magoou você?

Probst: Sim, muito. Eu estou lutando há anos por maior acessibilidade, e eu trato a minha deficiência de maneira aberta e franca. Antes de me tornar conhecida, as pessoas surdas quase não estavam presentes na mídia. Agora há discussões sobre se eu posso falar. Isso me deixou triste. (ROJKOV, 2012, tradução nossa) ${ }^{12}$

O excerto relata a experiência da política Probst após uma entrevista em um show de televisão, em que ela usou tanto a língua de sinais alemã como a língua alemã na modalidade oral. $\mathrm{O}$ interessante, quanto à identidade surda, nesse fragmento, está no fato de que Probst foi criticada no Twitter tanto pelos usuários surdos como pelos usuários ouvintes. Os surdos exigiam que ela usasse somente a língua de sinais ao falar sobre inclusão. Por um lado, isso mostra que estes esperavam que ela relacionasse sua identidade surda com a identidade linguística do surdo. Por outro lado, os comentários mostram a reivindicação dos usuários surdos pelo direito de reconhecimento e da promoção da sua identidade linguística e, portanto, de não ter de se assimilar linguisticamente ao mundo ouvinte. Contrariamente, os ouvintes consideraram menos a identidade surda de Probst do que sua identidade política, ao defender que ela precisava de uma boa voz para utilizá-la como ferramenta política. Com isso, os usuários demonstram que a ideia da inclusão ainda não se encontra estabelecida na esfera política.

No centro dessas críticas, localiza-se a política surda Probst, que se identifica tanto com sua atividade política quanto com sua surdez, a qual classifica de deficiência. Com as críticas, os usuários não somente negam a Probst o direito de utilizar a língua oral, mas também negam a sua identidade surda e política. Enquanto a identidade política é negada com base na ideia de que Probst não corresponde às expectativas relacionadas ao estereótipo profissional político de proferir discursos

12 Texto original em alemão: "Julia Probst: Ich habe bei der Sendung 'log in' Fragen zur Piratenpartei beantwortet. [...] Am nächsten Morgen las ich dann auf Twitter, dass meine Stimme nicht gut klang. Einige User schrieben, ich hätte nur die Gebärdensprache benutzen sollen.

ZEIT ONLINE: Was für User waren das?

Probst: Viele waren ebenfalls gehörlos. Sie meinten: Wenn ich über Inklusion rede, dann muss ich das auch in Gebärdensprache tun. Andere, nicht behinderte User schrieben, die Stimme sei das wichtigste Werkzeug eines Politikers. Aber die Gebärdensprache ist nun mal nicht meine Muttersprache. Und ich möchte sprechen!

ZEIT ONLINE: Hat Sie diese Kritik getroffen?

Probst: Ja, sehr. Ich kämpfe seit Jahren für mehr Barrierefreiheit, und ich gehe offen mit meiner Behinderung um. Bevor ich bekannt wurde, kamen gehörlose Menschen in den Medien kaum vor. Und nun gibt es Diskussionen darüber, ob ich überhaupt sprechen darf. Das hat mich traurig gemacht." 
orais em público, a identidade surda é negada pelos usuários surdos que esperam que ela represente a identidade surda (auto)estereotipada baseada também na característica linguística dos surdos. Infere-se, portanto, que os surdos criticam-na por não representar em público a identidade coletiva surda desejada por eles. O próximo trecho trata do tema da inclusão de maneira mais filosófica.

\begin{abstract}
Quem não quer discriminar pessoas desfavorecidas em todas as esferas da vida tem como objetivo, ao final das contas, a ampla eliminação de diferenças. Não obstante, as pessoas formam grupos e, muitas vezes, se definem emocionalmente com essas demarcações, como mostrou, por exemplo, o sociólogo Pierre Bourdieu. Isso pode se referir a povos, fãs de diferentes clubes de futebol, pessoas de diferentes extratos sociais, a velha e a nova geração, homens e mulheres - e no contexto da deficiência, por exemplo, os surdos-mudos e os não surdos-mudos.

A identidade, que nos é tão cara, e a inclusão podem, assim, entrar em uma tensão delicada. Até falar sobre discriminações pode ficar difícil, se tentamos, por exemplo, utilizar a língua consistentemente de uma maneira não discriminatória. Podemos chamar um surdo-mudo realmente de deficiente ou ele vive apenas em um mundo diferente da maioria das outras pessoas? (EKARDT, 2015, tradução nossa) ${ }^{13}$
\end{abstract}

$\mathrm{O}$ autor toca o tema da identidade no contexto da inclusão, afirmando que a ideia da eliminação de diferenças entra em conflito com a teoria sociológica da identificação com grupos. Ao discorrer sobre a inclusão, menciona como exemplo os surdos. Nesse contexto, usa a palavra alemã Taubstummer, traduzida aqui por surdo-mudo. Geralmente, o uso dessa expressão, tanto em alemão como em português, é considerado discriminatório e, inclusive, ignorante, pois ignora o fato de que os surdos geralmente falam, seja utilizando uma língua na modalidade oral, escrita ou visual-espacial ou outros meios de comunicação. Possivelmente essa expressão, no contexto, deve-se entender em relação com a sua afirmação de que é difícil "utilizar a língua consistentemente de uma maneira não discriminatória". Contudo, pode-se dizer que o autor conceitualiza uma identidade coletiva surda que se distingue por não poder articular-se.

Além disso, o autor tematiza diretamente a identidade coletiva surda ao questionar se os surdos se encaixam no grupo das pessoas com deficiência ou simplesmente fazem

13 Texto original em alemão: "Wer Benachteiligte in jeglichen Lebensbereichen nicht diskriminieren möchte, zielt letztlich auf eine weitgehende Aufhebung von Unterschieden ab. Doch Menschen bilden Gruppen und definieren sich emotional oft über diese Abgrenzungen, wie etwa der Soziologe Pierre Bourdieu gezeigt hat. Das kann Völker betreffen, Fans verschiedener Fußballvereine, Menschen verschiedener sozialer Hintergründe, die alte und die junge Generation, Männer und Frauen - und im Behindertenkontext etwa Taubstumme und Nicht-Taubstumme.

Identität, die uns allen lieb und teuer ist, und Inklusion können damit in eine heikle Spannung zueinander geraten. Sogar über Diskriminierungen zu sprechen, kann schwierig werden, wenn wir beispielsweise die Sprache konsequent nicht diskriminierend zu nutzen versuchen. Darf ein Taubstummer wirklich als behindert bezeichnet werden, oder lebt er einfach nur in einer anderen Welt als die Mehrheit der Mitmenschen?" 
parte de um "mundo diferente", uma expressão que pode ser interpretada, por exemplo, como comunidade cultural. Tendo em vista que esse pensamento expresso no artigo coincide com a autodefinição de uma parte dos surdos (SCHULTEIS, 2006), o fato de levar essa abordagem para a mídia de massa poderia sensibilizar os leitores em relação a esse assunto. Porém, pode-se observar, no próximo artigo, que esta questão é considerada secundária, posto que - em resposta direta ao fragmento anterior - o autor do artigo abaixo designa "a questão levantada" como "um pouco enganadora".

Neste contexto, a questão levantada por Ekardt, de que as pessoas surdas talvez não sejam deficientes, mas vivem em um "mundo diferente", é um pouco enganadora.

Melhor falarmos sobre a verba para surdos ${ }^{14}$ de que essas pessoas precisam para intérpretes e que em alguns estados federados não é concedida, e em outros estados federados não é concedida em quantidade suficiente. (ZANDER, 2015, tradução nossa) ${ }^{15}$

O autor contextualiza a inclusão relatando o descaso com os direitos de pessoas com deficiência devido à política europeia de austeridade. Com isso, ele redireciona o assunto dos surdos do contexto da inclusão da dimensão filosófica para uma dimensão da prática política, admoestando a disparidade regional quanto ao reembolso de custos para intérpretes da língua de sinais. Rejeitando a ideia de definir os surdos como uma comunidade cultural, o autor volta a categorizá-los como pessoas com deficiência.

O trecho seguinte retrata o caso isolado de uma aluna surda do ensino fundamental, chamada Melissa.

Na Baviera, os distritos são responsáveis pela ajuda de integração - neste caso, na forma de um intérprete da língua de sinais. Ao que parece, Melissa não tem problemas na escola. "Provavelmente todos estamos um pouco surpresos que ela esteja indo tão bem", diz a juíza Hohlen. O relatório semestral sobre Melissa informa que ela participa ativamente da aula e que seu desempenho está acima da média.

De acordo com o parecerista Rien, a aluna seria desafiada em um centro de apoio - em uma escola normal ela pode obter uma conclusão escolar melhor correspondente ao seu nível. (CORNELIUS, DPA; WOLF, 2012, tradução nossa) ${ }^{16}$

14 A "verba para surdos" (Gehörlosengeld) é um apoio financeiro para compensar os custos adicionais relacionados com a surdez.

15 Texto original em alemão: "Vor diesem Hintergrund ist die von Ekardt aufgeworfene Frage, ob taube Menschen vielleicht nicht behindert seien, sondern in einer 'anderen Welt' leben, eher irreführend. Reden wir lieber über das Gehörlosengeld, das diese Menschen für Dolmetscher benötigen und das in einigen Bundesländern gar nicht, in anderen nicht in ausreichender Höhe gewährt wird."

16 Texto original em alemão: "In Bayern sind für die Eingliederungshilfe die Bezirke zuständig - in diesem Fall in Form eines Gebärdendolmetschers. Probleme auf ihrer Schule scheint Melissa nicht zu haben. 'Es sind wohl alle ein wenig überrascht, dass es so gut läuft', sagt Richterin Hohlen. In Melissas Zwischenzeugnis stehe, dass sie am Unterricht aktiv teilnehme und ihre Leistungen überdurchschnittlich seien.

Gutachter Rien zufolge wäre die Schülerin in einem Förderzentrum unterfordert - an einer normalen Schule kann sie danach besser einen Abschluss erreichen, der ihrem Niveau entspricht." 
No excerto, reforça-se o estereótipo negativo de surdos como pessoas incapazes ou menos inteligentes, posto que o fato de Melissa não enfrentar problemas na escola e "que seu desempenho está acima da média" são relatados como algo surpreendente. Isso e a afirmação de que "a aluna seria desafiada em um centro de apoio" desqualificam também as escolas de apoio, assumindo que sua conclusão escolar é menos apreciada e de menor qualidade. Em paralelo, degradam-se, de maneira indireta, todos os alunos que frequentam esse tipo de escolas, sugerindo que são incapazes de chegar a um nível alto de escolaridade. Essa suposição nega as diferenças entre os alunos com deficiência e avilta a identidade dos surdos, assim como de todos os alunos de escolas de apoio. Melissa, enfatize-se, é representada como um caso extraordinário.

\subsection{Os surdos como qualquer aluno com deficiência}

Além de definir os surdos como uma subcategoria das pessoas com deficiência, existe também a tendência da mídia de dissolver ou ignorar essa subcategoria. No fragmento seguinte, os alunos com deficiência são tratados indiferentemente. $\mathrm{O}$ artigo relata a história educativa de um aluno autista - Sebastian - que parou de frequentar uma escola inclusiva porque não se sentia bem lá.

\footnotetext{
Uma possibilidade seria uma escola especial para surdos em Othmarschen, propõe a autoridade. Os pais permanecem céticos: o caminho para a escola é longo - e Sebastian teria possivelmente problemas na comunicação com as crianças surdas. (HOLLENSTEIN, 2015, tradução nossa) ${ }^{17}$
}

Esse trecho ilustra que, nesse caso, as autoridades tratam as escolas especiais como um lugar para qualquer aluno que não consiga adaptar-se ao sistema educacional regular. $\mathrm{O}$ aspecto da especialização do ensino na escola para surdos não é mencionado; o que se menciona é somente que o aluno autista poderia ter problemas de comunicação com as outras crianças. Desse modo, o jornal categoriza pessoas autistas e surdas indiretamente como pessoa com deficiência. Acrescentase, ainda, que, nesse excerto, alerta-se para o fracasso da inclusão e desqualificamse as escolas de apoio especial, negando seu foco especializado. No próximo

17 Texto original em alemão: "Möglich wäre eine Sonderschule für Gehörlose in Othmarschen, schlägt die Behörde vor. Die Eltern sind weiterhin skeptisch: Der Schulweg ist weit - und Sebastian hätte womöglich Probleme bei der Kommunikation mit den gehörlosen Kindern." 
fragmento, ao invés disso, as escolas de apoio são valorizadas como o lugar ideal para alunos com deficiências.

Assim, existem, por exemplo, escolas de apoio para crianças e jovens surdos, com deficiência física ou mental ou para aqueles com dificuldades de aprendizagem. A integração e a inclusão de alunos com deficiência nas escolas regulares têm sido disputadas faz muito tempo: enquanto alguns alertam para a discriminação e desvantagem por meio da separação deliberada e pedem a abertura de escolas regulares, outros temem que as pessoas com deficiência não recebam lá suficiente apoio, e que o nível de educação possa decair. (EBITSCH, 2012a, tradução nossa) ${ }^{18}$

O fragmento explica as diversas formas de escolas nas regiões diferentes da Alemanha. Por um lado, percebe-se uma diferenciação dos tipos de alunos com deficiência quando a autora aborda os diversos tipos de escolas de apoio. Por outro lado, no contexto da integração e inclusão, percebe-se a construção de dois grupos, separando os alunos com deficiência dos que não a possuem. A autora desenha dois cenários, refletindo duas atitudes diferentes sobre a inclusão. $\mathrm{O}$ primeiro cenário parte da situação do ensino segregativo, dizendo que, nessa situação, segundo algumas pessoas, o grupo dos alunos com deficiência encontra-se discriminado. $\mathrm{O}$ segundo cenário parte da situação do ensino inclusivo, dizendo que este poderia prejudicar tanto o grupo dos alunos com deficiência por falta de apoio adequado quanto os alunos sem deficiência devido à queda no nível do ensino.

Pela descrição dos cenários, pode-se deduzir que o único proveito da inclusão para o grupo dos alunos com deficiência consiste em não ser discriminado. Esse proveito contrapõe-se às possíveis consequências negativas da inclusão tanto para o grupo dos alunos com quanto para o grupo dos alunos sem deficiências. Simplificando: segundo o artigo, a política antidiscriminatória prejudica a educação de todos os alunos. Essa afirmação converte o entendimento comum da inclusão, que, geralmente, é considerada como uma medida para estabelecer a igualdade de oportunidades para pessoas desfavorecidas. No entanto, nesse artigo, a inclusão se resumiria a uma medida política sem efeitos positivos além da erradicação da discriminação escolar, trazendo desvantagens para todos os alunos. Consequentemente, segundo o jornal, os alunos com deficiência não são incluíveis e, além disso, culpáveis pela diminuição da qualidade do ensino.

18 Texto original em alemão: "So gibt es beispielsweise Förderschulen für gehörlose Kinder und Jugendliche, für körperlich oder geistig behinderte oder für solche mit Lernschwierigkeiten. Die Integration und Inklusion behinderter Schüler in Regelschulen ist seit langem umstritten: Während die einen vor Diskriminierung und Benachteiligung durch die bewusste Trennung warnen und die Öffnung der Regelschulen fordern, befürchten andere, dass Behinderte dort nicht genug Unterstützung erfahren und das Unterrichtsniveau sinken könnte." 
Em contrapartida, no próximo trecho deparamo-nos com a apresentação de um estudo que demonstra os efeitos positivos da educação inclusiva para os alunos com necessidades educacionais especiais. ${ }^{19}$

Um novo estudo do Instituto para o Desenvolvimento Qualitativo da Educação demonstra: as crianças com necessidades educacionais especiais que foram ensinadas em uma escola regular apresentam melhor desempenho do que alunos de escolas especiais. Mas até que ponto beneficiam os alunos não deficientes de aulas inclusivas? Eles não são mais prejudicados em seu ritmo de aprendizagem, porque precisam considerar os alunos fracos? Isto não influencia, ao final, negativamente as notas? (DÍAZ, 2014, tradução nossa) ${ }^{20}$

A autora do artigo conceitualiza dois grupos, gerando uma oposição dos alunos com e sem necessidades educacionais especiais (ou deficiência). Por um lado, atestase o benefício do ensino inclusivo para as pessoas com deficiência, e, por outro, se questiona esse benefício para os outros alunos. Com isso, criar-se-ia um conflito entre esses dois grupos. Em consequência, a imagem construída dos alunos com deficiência é bastante negativa, posto que se lhes atribui a culpa por uma possível influência negativa sobre as notas dos outros alunos. Mas, como se observa no próximo trecho, a mídia também contempla a situação das crianças com deficiência avaliando a educação inclusiva como "estressante para algumas crianças deficientes".

Muitos pais apreciam a escola especial como espaço de acolhimento, que proporciona proteção e estabilidade ao seu filho, enquanto a comparação com as crianças sem deficiência também pode ser experimentada como desmotivadora. Enquanto a inclusão é a exceção, não a regra, ela pode ser também estressante para algumas crianças deficientes. (EBITSCH, 2012b, tradução nossa) ${ }^{21}$

A autora afirma que a experiência da educação inclusiva pode ter efeitos negativos para algumas crianças com deficiência. Ao utilizar a palavra "algumas", ela evita uma generalização e, dessa forma, não conceitualiza os alunos com deficiência

19 O termo alunos com necessidades educacionais especiais pode se referir tanto a alunos com deficiência quanto a alunos superdotados. Porém, podemos deduzir a partir do contexto que, no exemplo citado, se refere somente a alunos com deficiência.

20 Texto original em alemão: "Eine neue Studie des Instituts zur Qualitätsentwicklung im Bildungswesen (IQB) belegt: Kinder mit sonderpädagogischem Förderbedarf, die an einer Regelschule unterrichtet wurden, weisen höhere Leistungen auf als Schüler in Förderschulen. Doch inwieweit profitieren die nichtbehinderten Schüler von inklusivem Unterricht? Werden sie nicht eher in ihrem Lerntempo gebremst, weil sie Rücksicht auf die Schwachen nehmen müssen? Leiden nicht letztlich die Noten?"

21 Texto original em alemão: "Viele Eltern schätzen den Schonraum Förderschule, der ihrem Kind auch Schutz und Stabilität bietet, während der Vergleich mit nichtbehinderten Kindern auch als demotivierend erlebt werden kann. Solange Inklusion die Ausnahme ist und nicht die Regel, kann sie für manche behinderte Kinder auch belastend sein." 
como um grupo homogêneo. Alguns surdos podem identificar-se com essa conceitualização; outros, não. Além disso, percebe-se que a autora não relaciona a experiência negativa à educação inclusiva em geral, somente enquanto esta "é a exceção", isto é, enquanto crianças com deficiência na aula regular não representam um estado de normalidade.

\subsection{Os surdos como parte de um grupo heterogêneo}

A última parte da apresentação dos resultados da análise consiste em um trecho apenas, dado que esse tipo de conceitualização não é muito comum na mídia alemã. O texto foi escrito por uma mulher com Síndrome de Asperger, uma forma de autismo. Ela frequentou uma escola inclusiva. Como a autora informa, sua síndrome foi atestada somente depois da conclusão escolar.

Meu comportamento não me parecia estranho e quase passou despercebido na minha nova escola. Nós éramos de qualquer maneira um grupo misturado de surdos, cadeirantes, não deficientes, autistas e alunos com TDAH [Transtorno do Déficit de Atenção com Hiperatividade]. (LINKE, 2014, tradução nossa) ${ }^{22}$

$\mathrm{O}$ que a autora descreve nesse fragmento, pode-se entender como sua experiência de fazer parte de um grupo heterogêneo. Portanto, ela não se percebia como uma pessoa excepcional. Com o artigo, a autora constrói a visão de um grupo único de alunos em que a diferença é a normalidade. Posto que ela menciona explicitamente os surdos, ela os inclui em uma subcategoria nesse grupo. Convém ressaltar que a autora informa que todos os alunos da sua classe foram aprovados no Abitur, a qualificação para a universidade. Assim, a autora não somente desqualifica o estereótipo de que pessoas com deficiências fossem incapazes e alunos mais fracos, mas também caracteriza as pessoas com deficiência como possuindo um desempenho alto, um aspecto muito valorizado nas sociedades meritocráticas.

\section{CONSIDERAÇÕES FINAIS}

Resumindo os resultados da análise, podemos afirmar que não se pode falar da construção de uma identidade coletiva surda na mídia, mas de várias identidades

22 Texto original em alemão: "Mein Verhalten kam mir nicht seltsam vor und fiel an meiner neuen Schule kaum auf. Wir waren sowieso ein bunter Haufen aus Gehörlosen, Rollstuhlfahrern, Nichtbehinderten, Autisten und AD(H)Slern." 
coletivas surdas, com aspectos contraditórias. Assim, os modelos de identidade são incompatíveis entre si. Por um lado, nos deparamos na mídia com os surdos como uma subcategoria de pessoas com deficiência. Mas dentro dessa subcategoria observam-se características contraditórias. Ora os surdos são inclúveis por meio da tecnologia auditiva ou com o auxílio de um intérprete, ora os surdos não são incluíveis porque utilizam outra língua. Ora são menos capazes que os outros alunos, ora mostram um desempenho acima da média. Ora se reconhece uma identidade linguística, ora não. Em outro caso, os surdos são categorizados como surdos-mudos, questionando simultaneamente a categorização dessa população como deficiente. Em ainda outra ocasião, a questão da identidade surda é declarada secundária no contexto da inclusão social.

Por outro lado, encontram-se os surdos definidos como uma subcategoria de alunos com deficiência. Essa subcategorização não se realiza sempre de modo explícito, pelo contrário, muitas vezes menciona-se somente a categoria superordenada pessoa/aluno com deficiência. Não obstante, as atribuições referem-se tanto a surdos como a qualquer outra subcategoria de pessoas com deficiência. Nesses casos, vemos também que se atribuem características contraditórias: ora são incluíveis, ora não são incluíveis; ora são beneficiados pela educação inclusiva, ora são prejudicados pela inclusão. Também deparamo-nos com a afirmação de que a inclusão na educação poderia diminuir a qualidade do ensino de modo geral.

Finalmente, existe também a conceitualização do surdo como qualquer outro aluno em um grupo heterogêneo, sem lhe atribuir nenhuma particularidade.

As observações resumidas até aqui se baseiam exclusivamente em categorizações e atribuições alheias. Essa circunstância remete a um resultado notável da análise: os surdos são quase excluídos do discurso midiático de importância nacional. Nos exemplos aqui apresentados, somente uma pessoa surda - uma política famosa - houve a possibilidade de se expressar em uma entrevista. Não obstante, até neste artigo, manifestam-se diferentes identidades surdas: a identidade como pessoa com deficiência e a identidade focalizada na particularidade linguística.

Relacionando os resultados da análise com as reflexões teóricas sobre identidades coletivas e estereótipos no contexto da inclusão escolar, podemos constatar que a mídia, em parte, contribui para a construção de dois grupos: as pessoas com e sem deficiência (ou necessidades educacionais especiais). A ideia de uma identidade coletiva heterogênea quase não está representada na mídia. Outrossim, encontram-se (re)produções do estereótipo negativo de surdos e de pessoas com deficiência relacionado às capacidades escolares. Posto que esses tipos 
de estereótipos podem ter efeitos negativos no desempenho das pessoas que se identificam com esses grupos, a mídia contribui - talvez inadvertidamente - para o fracasso escolar desses alunos.

Nota: Artigo relacionado com os projetos: Estudos das identidades surdas nas práticas sociais e discursivas inclusivas no Brasil e na Alemanba de Romana Castro Zambrano, bolsista PNPD/CAPES (2015-2017), e As narrativas do en e as construções identitárias coletivas e individuais do sujeito surdo: foco na escolaridade (PVD2955-2015) de Cleide Emília Faye Pedrosa.

\section{REFERÊNCIAS BIBLIOGRÁFICAS}

ASSMANN, J. (1988). Kollektives Gedächtnis und kulturelle Identität. In: Assmann, J.; Hölscher, T. (orgs.). Kultur und Gedäcbtnis. Frankfurt: Suhrkamp, pp. 9-19.

ASSMANN, J. (2000). Das kulturelle Gedächtnis. Scbrift, Erinnerung und politische Identität in den früben Hochkulturen. München: Beck.

ASSMANN, A.; ASSMANN, J. (1988). Schrift, Tradition und Kultur. In: Raible, W. (org.). Zwischen Festtag und Alltag. Zebn Beiträge zum Thema "Mündlichkeit und Scbriftlichkeit". Tübingen: Narr, pp. 25-50.

CASTRO ZAMBRANO, R. (2015)Diskursanalyse und mentale Prozesse: Sprachliche Strategien zur diskursiven Konstruktion nationaler Identität bei Hugo Chávez und Evo Morales. Frankfurt: Lang.

BABAD, E. Y.; INBAR, J.; ROSENTHAL, R. (1982). Pygmalion, Galatea, and the Golem: Investigations of biased and unbiased teachers. Journal of Educational Psychology, v. 74, $\mathrm{n}^{\circ} 4$, pp. 459-474.

BELZ, N. (2012). Die allmähliche Integration der Inklusion. Frankfurter Allgemeine Zeitung, 11/04/2012. Disponível em: http://www.faz.net/aktuell/politik/inland/schulbildungdie-allmaehliche-integration-der-inklusion-11714695.html. Acesso em: 04 jan. 2016.

BGG (2002) = Gesetz zur Gleichstellung behinderter Menschen (Behindertengleichstellungsgesetz - BGG) vom 27.04.2002. Zuletzt geändert durch Art. 12 Gv. 19.12.2007. Disponível em: http://www.gesetze-im-internet.de/bgg/BJNR146800002.html. Acesso em: 03 out. 2015.

BOURHIS, R. Y.; MAASS, A. (2005). Linguistic Prejudice and Stereotypes/Linguistisches Vorurteil und Stereotyp. In: Ammon, U. et al. Sociolinguistics/Soziolinguistik. An International Handbook of the Science of Language and Society/Ein internationales Handbucb zur Wissenschaft von Sprache und Gesellschaft. Berlin/New York: de Gruyter, v. 2, pp. 1587 1602. 
BRASIL. Lei n ${ }^{\circ}$ 13.005, de 25 de junho de 2014. Aprova o Plano Nacional de Educação - PNE e dá outras providências. Disponível em: http://www.planalto.gov.br/ CCIVIL_03/_Ato2011-2014/2014/Lei/L13005.htm. Acesso em: 24 nov. 2015.

CAPDEVILLE, G. (1994). Os sistemas escolares alemão, inglês e francês e a formação de seus professores. Em Aberto, v. 14, n 64, pp. 43-60. Disponível em: http://rbep.inep. gov.br/index.php/emaberto/article/view/1996. Acesso em: 16 out. 2015.

CASTELLS, M. (1999). O Poder da identidade. A era da informação: economia, sociedade e cultura. Vol. II. São Paulo: Paz e Terra.

CHARTERIS-BLACK, J. (2004). Corpus approaches to critical metaphor analysis. Basingstoke: Palgrave Macmillan.

CORNELIUS, C., DPA; WOLF (2012). Gehörloses Mädchen willweiter in die Grundschule. Süddeutsche Zeitung, 26/07/2012. Disponível em: http://www.sueddeutsche.de/bildung/ klage-um-finanzierung-eines-gebaerdendolmetschers-gehoerloses-maedchen-willin-die-schule-1.1422726. Acesso em: 04 jan. 2016.

DÍAZ, L. (2014). Gymnasiastin mit Down-Syndrom. Christ \& Welt in Die Zeit, 21/06/2014. Disponível em: http://www.zeit.de/gesellschaft/schule/2014-06/inklusiongymnasium. Acesso em: 04 jan. 2016.

EBITSCH, S. (2012a). Wo Ihr Kind am besten lernt. Süddeutsche Zeitung, 09/10/2012. Disponível em: http://www.sueddeutsche.de/bildung/schulformen-in-deutschlandwo-ihr-kind-am-besten-lernt-1.1482236. Acesso em: 04 jan. 2016.

EBITSCH, S. (2012b). Wann gemeinsames Lernen sinnvoll ist. Süddeutsche Zeitung, 15/10/2012. Disponível em: http://www.sueddeutsche.de/bildung/inklusion-stattfoerderschule-wann-gemeinsames-lernen-sinnvoll-ist-1.1482320. Acesso em: 05 jan. 2016.

EKARDT, F. (2015). Wie Chancengleichheit und Kapitalismus sich in die Quere kommen. Zeit Online, 15/072015. Disponível em: http://www.zeit.de/gesellschaft/2015-07/ inklusion-chancengleichheit-kapitalismus-kritik. Acesso em: 05 jan. 2016.

FAIRCLOUGH, N. (1992). Discourse and social change. Cambridge: Polity Press.

FAIRCLOUGH, N. (1995). Critical Discourse Analysis. Boston: Addison Wesley.

FAIRCLOUGH, N. (2003). Analysing discourse. Textual analysis for social research. London: Routledge.

FAIRCLOUGH, N.; WODAK, R. (1997). Critical Discourse Analysis. In: van Dijk, T. A. (org.). Discourse as Social Interaction. London: Sage, pp. 258-284.

FAUCONNIER, G. (1994). Mental spaces. Aspects of meaning construction in natural language. Cambridge: Cambridge University Press.

FAUCONNIER, G.; TURNER, M. (2002). The way we think. Conceptual Blendings and the mind's bidden complexities. New York: Basic Books.

FILLMORE, C. J. (1982). Frame Semantics. In: The Linguistic Society of Korea (org.). Linguistics in the morning calm. Seoul: Hanshin Publishing Company, pp. 111-137. 
GEERAERTS, D. (2006). Prospects and problems of prototype theory. In: Geeraerts, D. (org.). Cognitive Linguistics: Basic Readings. Berlin/New York: de Gruyter, pp. 141-165. GIESEN, B. (1999). Kollektive Identität. Die Intellektuellen und die Nation 2. Frankfurt: Suhrkamp. GOFFMAN, E. (1959). The Presentation of Self in Everyday Life. New York: Anchor.

GÜNTHER, K.-B. (2007). Gehörlosigkeit und Schwerhörigkeit. In: Borchert, J. (org.). Einfübrung in die Sonderpädagogik. München: Oldenbourg, pp. 77-109.

HALBWACHS, M. (1966). Das Gedächtnis und seine sozialen Bedingungen. Berlin/Neuwied: Luchterhand.

HALBWACHS, M. (1985). Das kollektive Gedächtnis. Frankfurt: Fischer.

HALL, S. (1996). Identidade cultural e diáspora. Revista do Patrimônio, nº 24, pp. 68-75.

HART, C. (2010). Critical Discourse Analysis and Cognitive Science: New perspectives on immigration discourse. Basingstoke: Palgrave Macmillan.

HART, C. (2014). Discourse, grammar and ideology. Functional and cognitive perspectives. London/ New York: Bloomsbury.

HOLLENSTEIN, O. (2015). Und wo soll er jetzt hin? Die Zeit, 15/04/2015. Disponível em: http://www.zeit.de/2015/14/autismus-bildung-schule-hamburg. Acesso em: 05 jan. 2016.

KLANDERMANS, B. (2002). How group identification helps to overcome the dilemma of collective action. American Behavioral Scientist, v. 45, n 5, pp. 887-900.

KOLLER, V. (2005). Critical discourse analysis and social cognition: evidence from business media discourse. Discourse \& Society, v. 16, n 2, pp. 199-224.

KRISTIANSEN, G. (2008). Idealized Cultural Models: The group as a variable in the development of cognitive schemata. In: Frank, R. M. et al. (orgs.). Body, language and mind. Vol. 2: Sociocultural situatedness. Berlin/New York: de Gruyter, pp. 409-432.

KRÖG, W. (2005). Einleitung. In: Mensch im Mittelpunkt (MIM); Verein TAFIE Ausserfern (orgs.). Herausforderung Unterstützung. Perspektiven auf dem Weg zur Inklusion. Lechaschau: MiM/TAFIE, pp. 3-6.

LAKOFF, G. (1987). Women, fire, and dangerous things. What categories reveal about the mind. Chicago: Chicago University Press.

LAKOFF, G.; JOHNSON, M. (1999). Philosopby in the flesh. The embodied mind and its challenge to Western thought. New York: Basic Books.

LAKOFF, G.; JOHNSON, M. (1980). Metaphors we live by. Chicago/London: University of Chicago Press.

LINKE, D. (2014). Inklusion hat mich gerettet. Süddeutsche Zeitung, 24/08/2014. Disponível em: http://www.faz.net/aktuell/feuilleton/debatten/eine-asperger-autistin-berichtet-13113454.html. Acesso em: 04 jan. 2016.

LÖWE, A. (1983). Gehörlosenpädagogik. In: Solarová, S. (org.). Geschichte der Sonderpädagogik. Stuttgart: Kohlhammer, pp. 12-48.

MANTOAN, M. T. E. (2004). O direito de ser, sendo diferente, na escola. Revista CEJ. Brasília, no 26, pp. 36-44. 
MEAD, G. H. (1934). Mind, Self, and Society. Ed. by Charles W. Morris. Chicago: University of Chicago Press.

MERTON, R. K. (1948). The self-fulfilling prophecy. The Antioch Review, v. 8, nº 2, pp. 193 210.

MISSLING, S.; ÜCKERT, O. (2014). Inklusive Bildung: Scbulgesetze auf dem Prüfstand. Berlin: Deutsches Institut für Menschenrechte. Disponível em: http://www.institut-fuermenschenrechte.de/monitoring-stelle-un-brk/publikationen/. Acesso em: 03 jan. 2016.

O'HALLORAN, K. (2003). Critical Discourse Analysis and Language Cognition. Edinburgh: Edinburgh University Press.

ONU (2012) = Organização das Nações Unidas. Convenção sobre os Direitos das Pessoas com Deficiência. $4^{\mathrm{a}}$ ed. Brasília: Presidência da República; Secretaria de Direitos Humanos; Secretaria Nacional de Promoção dos Direitos da Pessoa com Deficiência.

PANESAR, R. (2015). Vorurteilsfreie Pädagogik. Anti-Bias-Arbeit mit Lehrkräften. Disponível em: http://www.charta-der-vielfalt.de/service/publikationen/vielfalterkennen/unconscious-bias-im-oeffentlichen-sektor/vorurteilsfreie-paedagogik. html. Acesso em: 14 nov. 2015.

PRANTL, H. (2014). Soziale Stärke. Süddeutsche Zeitung, 16/06/2014. Disponível em: http:// www.sueddeutsche.de/bildung/inklusion-von-menschen-mit-behinderung-sozialestaerke-1.2000631. Acesso em: 04 jan. 2016.

REISIGL, M.; ZIEM, A. (2014). Diskursforschung in der Linguistik. In: Angermuller, J. et al. (orgs.). Diskursforschung: ein interdisziplinäres Handbuch. Vol. 1: Theorien, Methodologien, Kontroversen. Bielefeld: transcript, pp. 70-110.

ROJKOV, A. (2012). "Wenn mich jemand online runtermacht, geht mir das nahe". Zeit Online, 04/12/2012. Disponível em: http://www.zeit.de/politik/deutschland/2012-12/ piraten-julia-probst. Acesso em: 05 jan. 2016.

ROSENTHAL, R.; JACOBSON, L. (1968). Pygmalion in the classroom. Teacher expectations and student intellectual development. New York: Holt.

SCHUMANN, B. (2014). "Meilenstein für die inklusive Bildung". Disponível em: http:// bildungsklick.de/a/91629/meilenstein-fuer-die-inklusive-bildung/. Acesso em: 02 out. 2015.

SCHULTEIS, M. (2006). Deaf Culture. A subcultural approach to Deaf Communities in America and Germany. Tese de Magister em Ciências Culturais. Instituto de Ciências Culturais, Universidade de Leipzig, Leipzig. Disponível em: http://www.taubenschlag.de/ DiplarbuDiss. Acesso em: 03 jan. 2016.

SMITH, A. D. (2008). Nationalism. Theory, Ideology, History. Cambridge: Polity Press.

SPITZMÜLLER, J.; WARNKE, I. (2011). Diskurslinguistik. Eine Einführung in Theorien und Methoden der transtextuellen Sprachanalyse. Berlin/Boston: de Gruyter.

STEELE, C. M. (1997). A threat in the air: How stereotypes shape intellectual identity and performance. American Psychologist, v. 52, nº 6, pp. 613-629. 
STEELE, C. M.; ARONSON, J. (1995). Stereotype threat and the intellectual test performance of African Americans. Journal of Personality and Social Psychology, v. 69, $\mathrm{n}^{\circ}$ 5, pp. 797-811.

TAJFEL, H. (1981). Human Groups and social categories: Studies in Social Psychology. Cambridge: Cambridge University Press.

VAN DIJK, T. A. (1984). Prejudice in discourse. An analysis of etbnic prejudice in cognition and conversation. Amsterdam/Philadelphia: John Benjamins.

VAN DIJK, T. A. (1997). The Discourse-Cognition-Society Triangle. In: Cleve, G. et al. (orgs.). Wissenschaft, Macht, Politik: Interventionen in aktuelle gesellschaftliche Diskurse. Münster: Westfälisches Dampfboot, pp. 20-36.

VAN DIJK, T. A. (2002). Political discourse and political cognition. In: Chilton, P. A.; Schäffner, C. (orgs.). Politics as text and talk. Analytical approaches to political discourse. Amsterdam: Benjamins, pp. 204-236.

VAN DIJK, T. A. (2003). The discourse-knowledge interface. In: Weiss, G.; Wodak, R. (orgs.). Critical Discourse Analysis. Theory and interdisciplinarity. Houndsmills: Palgrave Macmillan, pp. 85-109.

VIOTTI, M. L. R. (2014). Educação básica e o ensino médio na Alemanha. In: Ministério de Relações Exteriores: Mundo Afora $n^{\circ} 11$ - Educação Básica e Ensino Médio. Brasília: Ministério de Relações Exteriores, pp. 22-33. Disponível em: http://dc.itamaraty. gov.br/publicacoes/mundo-afora-no-11-educacao-basica-e-ensino-medio. Acesso em: 03 jan. 2015.

VOGEL, H. (1999). Gebärdensprache und Lautsprache in der deutschen Taubstummenpädagogik im 19. Jabrbundert. Tese de Magister em Educação. Instituto de Educação, Universidade de Hamburg, Hamburg. Disponível em: http://sonos-info.ch/media/ e7eec37cfd6a348ffff804effffffd2.pdf. Acesso em: 20 aug. 2015.

WERNING, R. (2014). Stichwort: Schulische Inklusion. Zeitschrift für Erziebungswissenschaft, v. $17, n^{\circ} 4$, pp. 601-623.

WISOTZKI, K. H. (2008). Hörgeschädigtenpädagogik. In: Bleidick, U.; Ellger-Rüttgers, S. L. (orgs.). Bebindertenpädagogik - eine Bilanz. Bildungspolitik und Theorieentwicklung von 1950 bis zur Gegenwart. Stuttgart: Kohlhammer, pp. 169-185.

WODAK, R. (1996). Disorders of discourse. London: Longman.

WODAK, R. (2009). The discourse of politics in action: politics as usual. Basingstoke: Palgrave Macmillan.

WODAK, R.; MEYER, M. (orgs.) (2009a). Methods of Critical Discourse Analysis. London et al.: Sage.

WODAK, R.; MEYER, M. (2009b). Critical Discourse Analysis: history, agenda, theory and methodology. In: Wodak, R.; Meyer, M. (orgs.). Methods of Critical Discourse Analysis. London et al.: Sage, pp. 1-32. 
WODAK, R.; MEYER, M. (2015). Critical Discourse Studies: history, agenda, theory and methodology. In: Wodak, R.; Meyer, M. (orgs.). Methods of Critical Discourse Studies. E-book. London et al.: Sage.

ZANDER, M. (2015). Akademiker mit Trisomie 21. Zeit Online, 31/07/2015. Disponível em: http://www.zeit.de/gesellschaft/zeitgeschehen/2015-07/inklusion-chancengleichheit-kapitalismus. Acesso em: 05 jan. 2016.

ZIEM, A. (2008). Frames und spracbliches Wissen. Kognitive Aspekte der semantischen Kompetenz. Berlin: Walter de Gruyter.

Recebido: $13 / 03 / 2016$

Aceito: 26/09/2016 